\title{
Original Research \\ Pattern of adverse drug reactions reported by the community pharmacists in Nepal
}

\author{
Subish PALAIAN, Mohamed I.M. IBRAHIM, Pranaya MISHRA.
}

Received (first version): 12-Apr-2010 Accepted: 13-Jul-2010

\begin{abstract}
${ }^{*}$
The pharmacovigilance program in Nepal is less than a decade old, and is hospital centered. This study highlights the findings of a community based pharmacovigilance program involving the community pharmacists.

Objectives: To collect the demographic details of the patients experiencing adverse drug reactions (ADR) reported by the community pharmacists; to identify the common drugs causing the ADRs, the common types of ADRs; and to carry out the causality, severity and preventability assessments of the reported ADRs.

Methods: The baseline Knowledge-AttitudePractices (KAP) of 116 community pharmacists from Pokhara valley towards drug safety was evaluated using a validated (Cronbach alpha $=0.61$ ) KAP questionnaire having 20 questions [(knowledge 11 , attitude 5 and practice 4) maximum possible score 40]. Thirty community pharmacists with high scores were selected for three training sessions, each session lasting for one to two hours, covering the basic knowledge required for the community pharmacists for ADR reporting. Pharmacist from the regional pharmacovigilance center visited the trained community pharmacists every alternate day and collected the filled ADR reporting forms. Results: Altogether 71 ADRs, from 71 patients (37 males) were reported. Antibiotics/ antibacterials caused $42 \%(n=37)$ of the total ADRs followed by non steroidal anti-inflammatory drugs [25\% $(n=22)]$. Ibuprofen/paracetamol combination accounted for ten ADRs. The most common type of ADR was itching [17.2\% $(n=20)$, followed by generalized edema $[8.6 \%(n=10)]$. In order to manage the ADRs, the patients needed medical treatment in $69 \%(n=49)$ of the cases. Over two third $(69 \%)$ of the ADRs had a 'possible' association with the suspected drugs and a high percentage $(70.4 \%)$ were of 'mild (level 2)' type. Nearly two third [64.7\% $(n=46)]$ of the ADRs were 'definitely preventable'. Conclusion: The common class of drugs known to cause ADRs was antibacterial/ antibiotics. Ibuprofen/ Paracetamol combination use of the drug
\end{abstract}

\footnotetext{
*Subish PALAIAN. Discipline of Social and Administrative Pharmacy. School of Pharmaceutical Sciences, Universiti Sains Malaysia. Penang (Malaysia); and Department of Hospital and Clinical Pharmacy/ Pharmacology. Manipal Teaching Hospital/ Manipal College of Medical Sciences. Pokhara (Nepal).

Mohamed I.M. IBRAHIM. Discipline of Social and Administrative Pharmacy. School of Pharmaceutical Sciences, Universiti Sains Malaysia. Penang (Malaysia). Pranaya MISHRA. Department of Pharmacology. Saba University School of Medicine. Saba, (Netherlands Antilles).
}

was responsible for more number of ADRs and the most common ADRs were related to dermatological system. Strengthening this program might improve safe use of medicines in the community.

Keywords: Adverse Drug Reaction Reporting Systems. Community Pharmacy Services. Pharmacists. Nepal.

\section{PATRÓN DE LAS REACCIONES ADVERSAS COMUNICADAS POR FARMACÉUTICOS COMUNITARIOS EN NEPAL}

\section{RESUMEN}

El programa de farmacovigilancia de Nepal tiene menos de una década de antigüedad, y está centrado en los hospitales. Este estudio muestra los resultados de un programa de farmacovigilancia comunitario, que involucra a farmacéuticos comunitarios.

Objetivos: Recoger detalles demográficos del número de pacientes que sufren reacciones adversas a medicamentos (RAM) comunicadas por farmacéuticos comunitarios; identificar los medicamentos que causan las RAM y los tipos comunes de RAM; y realizar las evaluaciones de causalidad, gravedad y preventabilidad de las RAM reportadas.

Métodos: Se evaluó, mediante un cuestionario validado (Cronbach alfa $=0.61) 20$ preguntas [(conocimiento 11 , actitud 5 and práctica 4) máxima puntuación posible score 40], el valor inicial de Conocimiento-Actitudes-Práctica (KAP) de 116 farmacéuticos comunitarios del valle de Pokhara. Se selección a los 30 farmacéuticos comunitarios con puntuaciones más altas para realizar 3 sesiones formativas, cada sesión duraba de una a dos horas, que cubrían los conocimientos básicos que requerían los farmacéuticos para comunicar RAM. Los farmacéuticos del centro regional de farmacovigilancia visitaron a los farmacéuticos comunitarios formados en días alternos y recogieron las comunicaciones rellenas. Resultados: Se comunicaron 71 RAM de 71 pacientes (37 hombres). Los antibióticos/antibacterianos causaron el $42 \%$ $(n=37)$ del total de RAM, seguidos de los antiinflamatorios no esteroidicos $[25 \%(n=22)]$. La combinación ibuprofeno/paracetamol totalizó 10 RAM. El tipo de RAM más frecuente fue el picor [17.2 \% ( $\mathrm{n}=20)$ ], seguido del edema generalizado [8.6\% $(n=10)]$. Para resolver las RAM, el 69\% del total de los pacientes $(n=49)$ requirió tratamiento médico. Mas de 2 tercios de las RAM (69\%) tenia una 'posible' asociación con el medicamento 
sospechoso, y un alto porcentaje $(70.4 \%)$ eran de tipo 'suave (nivel 2)'. Cerca de 2 tercios de las RAM [64.7\% (n=46)] eran 'claramente prevenibles'.

Conclusión: El grupo más común que causo RAM fueron los antibacterianos/antibióticos. La combinación ibuprofeno/paracetamol fue responsable del mayor numero de RAM y las RAM más frecuentes estaban relacionadas con el sistema dermatológico. Reforzar este programa podría mejorar el uso seguro de medicamentos en la comunidad.

Palabras clave: Sistemas de comunicación de reacciones adversas de medicamentos. Servicios de farmacias comunitarias. Farmacéuticos. Nepal.

\section{INTRODUCTION}

Nepal is a developing country landlocked between China and India, with poor healthcare indicators. ${ }^{1}$ The geography of the country varies from plain lands to high altitude mountains. A significant portion of the country has a poor transportation and infrastructure. The qualified medical doctors in the country often do not practice in the rural and remote areas and hence the rural patients rely upon local healthcare practitioners for their healthcare needs. The health posts and the primary health centers in the rural areas are manned by community health assistants who do not possess a medical qualification. In addition, the doctor-patient ratio in Nepal is also very low $(1: 23000)^{2}$ The hilly terrain, poor socioeconomic status, high cost of modern medicines and non-availability of qualified doctors in rural areas, limits the access to modern healthcare by the general public. These factors led to the flooding of a high number of retail pharmacies in the country. The number of retail pharmacies outnumbers the number of health centers. ${ }^{3}$ The retail pharmacists do not collect a consultation charge unlike the medical doctors who opts a high consultation charges for every patient. All these factors collectively makes the retail pharmacies to be the first point of contact with the healthcare system by general public, thus giving a high opportunity for self-medication. ${ }^{4}$ Self-medication is known to contribute to Adverse Drug Reactions (ADRs) either by the drug itself or by causing an interaction with a prescription drug. Moreover there is evidence that the retail pharmacists themselves prescribe and dispense medications. ${ }^{5}$ The knowledge levels of retail pharmacists often goes beyond their technical skills and expertise. ${ }^{6}$ These retail pharmacists usually has a two year Diploma in Pharmacy (D.Pharm) or four year Bachelor in Pharmacy (B.Pharm) qualifications. A few of them possess a two week orientation program conducted by the national drug regulatory authority of Nepal, which is considered as a minimum qualification for registering a retail pharmacy. All the above mentioned problems collectively increase the risk for ADRs in the community settings of Nepal.
The concept of ADR monitoring in Nepal is in the stage of infancy. However, the Department of Drug Administration (DDA), the national drug regulatory authority, has under taken steps to establish an ADR monitoring program in Nepal. In the year 2006, Nepal has been given a member status by the Uppsala Monitoring Center, Sweden, the WHO collaborating Center for International Drug Monitoring. The ministry of health and population has designated DDA as the national center for ADR monitoring. ${ }^{7}$ Four regional centers are functioning under the national centers at present. These centers are located at teaching hospitals namely Tribhuvan University Teaching Hospital (TUTH) Kathmandu; Nepal Medical College, Kathmandu; KIST Medical College, Lalitpur; and Manipal Teaching Hospital (MTH) Pokhara, Nepal. These centers collect the ADR reports and send to the national center at DDA through the 'vigiflow online' (the WHO database) program.

The existing system of ADR monitoring in the country is beneficial only in reporting the ADRs that occur in hospital setups. This system remains unanswered for reporting ADRs that occur with over the counter (OTC) medications and in the ambulatory patient settings. This had led to the development of community based ADR reporting and monitoring system which could play an active role in collecting reports of ADRs occurring at the community level. ${ }^{8}$ The regional pharmacovigilance center of Western Nepal has been involved in reporting the ADRs occurring in the MTH. The members from the department of hospital and clinical pharmacy, and pharmacology are involved in the center. In the beginning the center did not focus towards the ADRs occurring in the community. Recently, in the year 2008, the members of the center have decided to setup a community based Pharmacovigilance system in which the community pharmacists report the ADRs. The outcome of such an initiative taken by the center is presented in the present article. Thus, the study was conducted with the following objectives:

1. To collect the demographic details of the patients experiencing adverse drug reactions in the community

2. To identify the common drugs causing the adverse drug reactions

3. To identify the common types of adverse drug reactions

4. To carry out the causality, severity and preventability assessments of the reported adverse drug reactions

\section{METHODS}

Study design: A cross sectional study evaluating the pattern of ADRs was carried out by analyzing the filled ADR reporting forms received from the community pharmacists (Figure 1 ).

Selection of community pharmacists: The baseline KAP of 116 community pharmacists from Pokhara valley towards drug safety was evaluated using a validated (Cronbach alpha of 0.61) KAP 
questionnaire having 20 questions [(knowledge $=11$, attitude $=5$ and practice $=4$ ) maximum possible score 40]. Thirty community pharmacists with higher scores were selected for the training. Among these 30 , six were initially tested as a pilot group (Figure 1).



Figure 1. Selection of participants and the study design

Development of ADR reporting form: An ADR reporting form was developed by the regional pharmacovigilance center and was used in the research. The reporting form had information on reporter, patient details and information on the reaction and medications. A pilot study was initially carried out with six community pharmacists and their inputs were taken while designing the ADR reporting form.

Training the community pharmacists: The training for pilot group (six community pharmacists) included three sessions spreaded over two months, covering the basic information and expertise needed to identify and report ADRs by filling the ADR reporting forms. After completion of the training for pilot group, the test group also received three sessions of training similar to the pilot group but spreaded over six months duration.

Method of collecting ADR reports: The pharmacists from the regional pharmacovigilance center visited the trained community pharmacists every alternate day and collected the filled ADR reporting forms. Any additional help needed for the community pharmacists were provided by the pharmacovigilance center pharmacists.

Data analysis: All the ADRs reported to the regional pharmacovigilance centre by the community pharmacists were collected. The demographic details were analyzed. The causality, severity and preventability assessments were carried as per the Naranjo ${ }^{10}$, Hartwig ${ }^{11}$ and Modified Schumock and Thornton scales ${ }^{12}$, respectively.

\section{RESULTS}

During the study period, 71 cases of ADRs from 71 patients were reported and the details are summarized below.

Demographic details of the patients experiencing ADRs: Among the total 71 patients, $52.1 \% \quad(n=37)$ were males and the remaining $47.8 \%(n=34)$ were females. Twenty two $(30.9 \%)$ of the patients were within 20 years of age, $50.7 \%(n=36)$ were between 21 to 40 years of age, $14 \%(n=10)$ were between $41-60$ years of age and $4.2 \%(n=3)$ were more than 60 yrs of age.

Onset of the ADRs: In ten cases (14\%), the patient was exposed to the suspected drug for less than a day; in $20(28.1 \%)$ patients, $1-2$ days; in $10(14 \%)$ patients, 3-4 days; in 10 (14\%) patients, 5-6 days; in $5(7 \%)$ patients, 7-8 days; in $5(7 \%)$ patients, more than 8 days in one $(1.4 \%)$ patients. The duration of use of the suspected drug was not available in $20(28.1 \%)$ patients.

Suspected drug category causing ADRs: More number (42\%) of ADRs was caused by Antibiotics/antibacterial class of drugs. Further details on the suspected drug categories responsible for causing the ADRs are listed in Table 1.

\begin{tabular}{|l|c|c|}
\hline \multicolumn{3}{|c|}{ Table 1. Suspected drug category causing ADRs ( $\mathrm{n}=88)$} \\
\hline \multicolumn{1}{|c|}{ Drug category } & Number & Percentage \\
\hline Antibiotics/ antibacterial & 37 & 42.0 \\
\hline NSAIDs & 22 & 25 \\
\hline Vitamins & 4 & 4.5 \\
\hline Antiamoebics & 4 & 4.5 \\
\hline Antifungals & 3 & 3.4 \\
\hline Antisecretory agents & 4 & 4.5 \\
\hline Sex hormones & 4 & 4.5 \\
\hline Miscellaneous & 10 & 11.3 \\
\hline
\end{tabular}

Top ten drugs causing the ADRs: Of the 71 reports, 10 were caused by the fixed dose combination (FDC) Ibuprofen/ paracetamol. The most common drugs responsible for causing the ADRs are listed in Table 2.

\begin{tabular}{|l|c|}
\hline \multicolumn{2}{|c|}{ Table 2. Top ten drugs causing the ADRs } \\
\hline \multicolumn{1}{|c|}{ Drugs } & No. reports \\
\hline Tab. Ibuprofen/ paracetamol combination & 10 \\
\hline Cap. Amoxycillin & 8 \\
\hline Cap. Ampicillin/ cloxacillin combination & 6 \\
\hline Tab. Metronidazole & 5 \\
\hline Tab. Diclofenac & 5 \\
\hline Inj. Ceftriazone & 4 \\
\hline Inj. Gentamicin & 2 \\
\hline Tab. Folic acid & 2 \\
\hline Cap. Omeprazole & 2 \\
\hline $\begin{array}{l}\text { Tab. Paracetamol+phenylephedrine+ } \\
\text { chlorpheniramine maleate combination }\end{array}$ & 4 \\
\hline
\end{tabular}

Types of adverse drug reactions: The types of ADRs observed are listed in Table 3. System affected by adverse drug reactions $(n=116)$ : The most affected system by the ADRs was dermatological (37.9\%; $n=44)$, followed by gastrointestinal system $(18.9 \% ; \quad n=22)$, cardiovascular (11.2\%; $n=13)$, central nervous system $(7.7 \% ; n=9)$, immune system $(5.1 \% ; n=6)$, ocular (4.3\%; $n=5)$, hematological $(2.5 \% ; n=3)$, endocrine $(1.7 \% ; n=2)$ and miscellaneous $(10.3 \%$; $n=12)$. 


\begin{tabular}{|c|c|c|}
\hline Reaction type & No. of reports & Percentage \\
\hline Itching & 20 & 17.2 \\
\hline Vomiting & 10 & 8.6 \\
\hline Macular rashes & 9 & 7.7 \\
\hline Swelling & 8 & 6.8 \\
\hline Abdominal pain & 6 & 5.1 \\
\hline Fever, rigor and chills & 5 & 4.3 \\
\hline Tingling in body, giddiness & 5 & 4.3 \\
\hline Contact dermatitis & 4 & 3.4 \\
\hline Generalized itchy maculopapular rashes & 3 & 2.5 \\
\hline Blurred vision & 2 & 1.7 \\
\hline Diarrhea & 2 & 1.7 \\
\hline Sore throat/tonsillitis/fever & 2 & 1.7 \\
\hline Miscellaneous & 18 & 15.5 \\
\hline
\end{tabular}

Treatment of the reaction, action taken and outcome of the suspected ADRs: Of the 71 patients, $49(69 \%)$ needed a medical treatment for managing the ADRs. Further details on various treatment methods, action taken and outcome of the suspected ADRs are listed in Table 4.

Causality, severity and preventability of the reported ADRs: The causality assessment, severity assessment and preventability assessment of the reported ADRs are listed in Table 5.

Table 4. Treatment of the reaction, action taken and outcome of the reaction

\begin{tabular}{|l|l|c|c|}
\hline Features & \multicolumn{1}{|c|}{ Parameters } & $\begin{array}{c}\text { Numbe } \\
\mathrm{r}\end{array}$ & $\begin{array}{c}\text { Percentag } \\
\mathrm{e}\end{array}$ \\
\hline \multirow{3}{*}{$\begin{array}{c}\text { Treatmen } \\
\text { Outcome }\end{array}$} & Medical treatment & 49 & 69.0 \\
\cline { 2 - 4 } & $\begin{array}{l}\text { Non medical } \\
\text { treatment }\end{array}$ & 5 & 7.0 \\
\cline { 2 - 4 } & Unknown & 17 & 23.9 \\
\hline & $\begin{array}{l}\text { Recovered/resolve } \\
\mathrm{d}\end{array}$ & 27 & 38.0 \\
\cline { 2 - 4 } & $\begin{array}{l}\text { Not recovered/not } \\
\text { resolved }\end{array}$ & 3 & 4.2 \\
\cline { 2 - 4 } & Unknown & 41 & 57.7 \\
\hline \multirow{2}{*}{$\begin{array}{l}\text { Action } \\
\text { taken }\end{array}$} & Drug withdrawn & 33 & 46.4 \\
\cline { 2 - 4 } & Dose reduced & 2 & 2.8 \\
\cline { 2 - 4 } & Dose increased & 2 & 2.8 \\
\cline { 2 - 4 } & Dose not changed & 8 & 11.2 \\
\cline { 2 - 4 } & Unknown & 26 & 36.6 \\
\hline
\end{tabular}

\section{DISCUSSION}

Self medication is a common problem in both developed and developing countries. ${ }^{13}$ In Nepal retail pharmacists are the first point of contact to the patients $^{2}$ and hence play an important role in the healthcare system. Data from Nepal suggest improper drug use by the retail pharmacists. ${ }^{5,14}$ They are known to diagnose, prescribe and dispense medications. Such activity of community pharmacists who had poor qualifications and training can lead to irrational drug use. It may results in ADRs. ADR is considered to be one of the major causes of mortality in developed countries. ${ }^{15}$ In Nepal the concept of ADR reporting is new and there is paucity in the data regarding drug safety. A few studies that are already reported are hospital based studies. ${ }^{16-18}$ In general, the health professionals in Nepal has a poor practice of ADR reporting to the national pharmacovigilance program. A preliminary study from the country reported a poor understanding among the clinicians, pharmacists and nurses regarding ADR reporting and pharmacovigilance. ${ }^{19}$ The present study analyzed the pattern of ADRs reported by the community pharmacists to the regional pharmacovigilance center, Western Nepal. Thus, making it the first kind of its study in the country and from developing countries.

\begin{tabular}{|c|c|c|c|}
\hline Features & Parameters & No. of reports & Percentage \\
\hline \multirow[t]{4}{*}{ Causality } & Possible & 49 & 69.0 \\
\hline & Probable & 22 & 30.9 \\
\hline & Definite & - & - \\
\hline & Not carried out & - & - \\
\hline \multirow[t]{8}{*}{ Severity } & Mild (Level 1) & 19 & 26.7 \\
\hline & Mild (Level 2) & 50 & 70.4 \\
\hline & Moderate (Level 3) & 2 & 2.8 \\
\hline & Moderate [Level 4(a)] & - & - \\
\hline & Moderate [Level 4(b)] & - & - \\
\hline & Severe (Level 5) & - & - \\
\hline & Severe (Level 6) & - & - \\
\hline & Severe (Level 7) & - & - \\
\hline \multirow{4}{*}{ Preventability } & Definitely preventable & 46 & 64.7 \\
\hline & Probably preventable & 13 & 18.3 \\
\hline & Not preventable & - & - \\
\hline & Not carried out ${ }^{*}$ & 12 & 16.9 \\
\hline
\end{tabular}


Upon training, the community pharmacy practitioners started reporting the ADRs to the regional pharmacovigilance center. During six months, they reported 71 ADR reports. The analysis of these 71 ADR reports revealed the sex distribution of the patients experiencing ADRs to be almost equal. In general, female are prone to cause ADRs. ${ }^{20}$ It is however, difficult to generalize as the number of patients was low.

Analgesics were the second most common class of drugs implicated for causing ADRs. Analgesics have caused several ADRs including gastric problems. Many times, they are used as OTC by the general public. The community pharmacist can play an important role in minimizing these ADRs by providing simple information to the patients regarding the precautions to be taken while taking medicines like either before or after food accordingly, and having more water with the medicine. In Spain, a pharmacist mediated intervention at community pharmacies improved the practice of adequate gastroprotection for patients asking for NSAIDS. ${ }^{21}$

We found antibiotics to be the most common class of drugs causing ADRs. The irrational use of antibiotics/antibacterial by community pharmacy practitioners has already been demonstrated by researchers a decade ago in Nepal. ${ }^{14}$ Moreover; in Nepal the community pharmacists dispense antimicrobials without a prescription. Few studies from the hospital settings in Nepal have already raised concerns regarding irrational antimicrobial use. ${ }^{22-24}$ Though, it is a common problem in both hospital and community settings, the impact may be higher in the community since antimicrobials are available even without having a prescription.

We found the ibuprofen/paracetamol to have caused more number of ADRs. Use of ibuprofen/paracetamol combinations is common in Nepal. ${ }^{25,26}$ Since it is an OTC medication; very often the patients consider these medications to be very safe. However, this medication is not approved in many countries and hence not available. There is also a claim that this combination is irrational. ${ }^{27}$ This finding suggests the need for more vigilance regarding the dispensing of OTC products by the retail pharmacists.

More number of ADRs reported was related to dermatological system suggesting topical ADRs. Topical ADRs are usually mild. However, they can contribute to significant economic loss 28 and impairment in quality of life of patients. Among the total 71 patients, 13 of them required medical treatment for ADRs and in 14 of the cases the suspected drugs were withdrawn. The skin and the mucosa are the commonest sites for initial presentation of many ADRs. In general, it is easy to identify a cutaneous ADR. The community pharmacy practitioners can play a vital role in minimizing the cutaneous ADRs by educating the patients regarding common early symptoms (eg, erythematous rash, edema, urticaria, mucosal erosions, itching, and burning of skin) especially during the start of the therapy.
Slightly more than two third (69\%) of the ADRs required a medical treatment in managing the ADRs. Thus, there is an economic burden to the patient experiencing the ADR in addition to the suffering and impaired quality of life. A preliminary evaluation of the cutaneous ADRs reported to the regional pharmacovigilance center reported a cost burden of USD $1.58(S D=1.41)$ for drug therapy. ${ }^{28}$ Though this finding included the ADRs occurring in the hospital, it provides a rough idea on the economic impact of the ADRs in Nepal.

In this study, 46 (nearly $64.7 \%$ ) of the total ADRs to be definitely preventable. It is well established that more than half of the ADRs are preventable with appropriate care. ${ }^{29}$ Since the ultimate objective of a pharmacovigilance program is to minimize the occurrence of similar ADRs in the future; one should take adequate steps in preventing the ADRs.

Limitations: Our study was conducted for a short period of time (six months) and included only a few (30) community pharmacists. Similar studies covering more retail pharmacists for a longer period of time are needed to validate our finding. Moreover, there is high possibility of under reporting by the community pharmacists.

Future directions: The present study was preliminary one which evaluated the ADRs reporting pattern by community pharmacists in a developing country like Nepal. Similar training programs are needed for other community pharmacists in order to strengthen the program. In addition, measures have to be taken to sustain the program. This can be achieved by involvement of professional pharmacy associations in the country and commitment and vision from the national pharmacovigilance center. The community pharmacists should also be oriented to send the reports directly to the regional pharmacovigilance center in spite of the pharmacovigilance center staffs visiting the community pharmacists to collect the reports.

\section{CONCLUSIONS}

The study was successful in analyzing the pattern of ADRs reporting by retail pharmacists. The common class of drugs known to cause ADRs was antibacterial/ antibiotics. Ibuprofen/paracetamol combination was the drug responsible for more number of ADRs and the most common ADRs were related to dermatological system. Upon strengthening the community based pharmacovigilance system there can be more rational use of medicines in community. It will also help in minimizing the occurrence of ADRs in the community.

\section{ACKNOWLEDGEMENTS}

The authors acknowledge Mr. Arjun Poudel, Mr. Saval Khanal and Mr. Kadir Alam, Pharmacists from Manipal Teaching Hospital for helping us in the data collection and conducting the pilot study. Authors also thank Mr. Sanjaya KC, Department of Biochemistry and Mr. Anil Sah Hospital Pharmacist, Department of Hospital and Clinical Pharmacy, 
Manipal Teaching Hospital for their help in conducting the training programs. Similarly, the authors would also like to acknowledge six of the retail Pharmacists from the Western region of Nepal namely Mr. Arjun Bahadur Khatri, Mr. Kamal Puri, Mr. Krishna Prasad Pandey, Mr. Maheshwor Giri, Mr. Milan Sigdel and Mr. Suresh Tiwari from Arjun Medical Hall, Ayu Pharmacy, Sancho Medico Pharma, New Pokhara Pharmacy, City Pharmacy and Sachetana Medical Hall respectively for their active participation in the training and reporting of the suspected ADRs.

\section{CONFLICT OF INTEREST}

None.

The authors express gratitude to the Health Action International-Asia Pacific (HAl-AP) for their support in funding the project.

\section{References}

1. Nepal health system profile (2007) [Online], [Accessed on 22nd December 2008]. Available from the World Wide Web http://www.searo.who.int/LinkFiles/Country_Health_System_Profile_8-Nepal.pdf

2. Sharma, HB, Gautam, RP, Vaidya, S. Eds. District development profile of Nepal. Kathmandu, Informal Sector Research and Study Center, 2001

3. Kafle KK, Gartoulla RP, Pradhan YM, Shrestha AD, Karkee SB, Quick J D. Drug retailer training: experiences from Nepal. Soc Sci Med. 1992;35(8):1015-1025

4. Kafle KK, Madden JM, Shrestha AD, Karkee SB, Das PL, Pradhan YM, Quick JD. Can licensed drug sellers contribute to safe motherhood? A survey of the treatment of pregnancy related anemia in Nepal. Soc Sci Med. 1996;42(11):15771588.

5. Blum NL. Rational pharmaceutical management project United States Pharmacopoeia: Drug information Development. A case study, Nepal Available at www.usp.org/pdf/EN/dqi/nepalCaseStudy.pdf (Accessed on 12th December 2009)

6. Das BP, Deo SK, Jha N, Rauniar GP, Naga Rani MA. Knowledge, attitudes and practices (KAP) regarding the management of diarrhea by pharmacists and licensed drug sellers in eastern Nepal. Southeast Asian J Trop Med Public Health. 2005;36(6):1562-1567.

7. Drug Bulletin of Nepal. 2004/2005; 15 (2) Available at http://www.dinon.org/publications/dbn-vol16.pdf (Accessed on May 21st 2008)

8. Palaian S, Izham MI, Mishra P. Developing a community based Pharmacovigilance program in Western Nepal: a significant initiative to ensure drug safety. J Clin Diagnos Res. 2008;2:905-906.

9. Palaian S, Mohamed Izham MI, Mishra P, Alam K, Poudel A, Khanal S. ADR reporting by community pharmacists in Nepal. J Pharm Pract Res. 2008;38:331-332.

10. Naranjo CA, Busto U, Sellers EM, Sandor P, Ruiz I, Roberts EA, Janecek E, Domecq C, Greenblatt DJ. A method for estimating the probability of adverse drug reactions. Clin Pharmacol Ther. 1981;30:239-245

11. Hartwig SC, Siegel J, Schneider PJ. Preventability and severity assessment in reporting adverse drug reactions. Am J Hosp Pharm. 1992;49:2229-2232

12. Schumock GT, Thornton JP. Focusing on the preventability of adverse drug reactions. Hosp Pharm. 1992;27:538.

13. Stein CM, Gora NP, Macheka BM. Self-medication in urban and rural Zimbabwean communities. Br J Clin Pharmacol. 1989;27:741-747.

14. Wachter DA, Joshi MP, Rimal B. Antibiotic dispensing by drug retailers in Kathmandu, Nepal. Trop Med Int Health. 1999;4:782-788

15. Lazarou J, Pomeranz BH, Corey PN. Incidence of adverse drug reactions in hospitalized patients: a meta-analysis of prospective studies. JAMA. 1998;279(15):1200-1205.

16. Palaian S, Mishra P, Shankar PR. Systemic adverse drug reactions: a preliminary report from the regional pharmacovigilance center, western Nepal. Pak J Pharm Sci. 2008;21(4):465-467.

17. Jha N, Bajracharya O, Namgyal T. Prevalence of adverse drug reactions with commonly prescribed drugs in different hospitals of Kathmandu valley. Kathmandu Univ Med J (KUMJ) 2007;5(4):504-510.

18. Shrestha R, Shakya S, Bista D. Case studies of hospitalized patients due to drug related complications. Kathmandu Univ J Sci Eng Technol 2006; 2 http://www.ku.edu.np/kuset/second_issue/o2/Rajeev.pdf (Accessed on 3rd January, 2010)

19. Palaian S, Izham MIM, Mishra P. Evaluation of the knowledge, attitude and practices on adverse drug reactions and pharmacovigilance among healthcare professionals in a Nepalese hospital- a preliminary study. Int J Pharmacol. 2008;6(1).

20. Lee A, Thomas SHL. Adverse drug reactions. In: Walker R and Edward C. Clinical pharmacy and Therapeutics, 2003, $3^{\text {rd }}$ edition Churchill Livingstone, 33-46.

21. Ibañez-Cuevas V, Lopez-Briz, E, Guardiola-Chorro, MT. NSAID induced Gastropathy Prevention Programme Group. Pharmacist intrvention reduces gastropathy risk in patients using NSAIDs. Pharm World Sci. 2008;30:947-954.

22. Shankar PR, Partha, P, Shenoy N, Brahmadathan KN. Investigation of antimicrobial use pattern in the intensive treatment unit of a teaching hospital in western Nepal. Am J Infect Control. 2003;31:410-414.

23. Paudel KR, Sharma M, Das BP. Prevalence of antimicrobial chemotherapy in hospitalized patients in the department of internal medicine in a tertiary care center. Nepal Med Coll J. 2008;10:91-95.

24. Khanal B, Sharma SK, Bhattacharya SK, Bhattarai NR, Deb M, Kanungo R. Antimicrobial susceptibility patterns of Salmonella enterica serotype typhi in eastern Nepal. J Health Popul Nutr. 2007;25:82-87.

25. Sarkar C, Das B, Baral P. Analgesic use in dentistry in a tertiary hospital in western Nepal. Pharmacoepidemiol Drug Saf. 2004; 13: 729-733. 
Palaian S, Ibrahim MIM, Mishra P. Pattern of adverse drug reactions reported by the community pharmacists in Nepal. Pharmacy Practice (Internet) 2010 Jul-Sep;8(3):201-207.

26. Palaian S, Shankar PR, Hegde C, Hegde M, Ojha P, Mishra P. Drug utilization pattern in dental outpatients in tertiary care teaching hospital in western Nepal. N Y State Dent J. 2008;74:63-67.

27. Poudel A, Palaian S, Shankar P.R, Jayasekera J, Izham MIM. Irrational fixed dose combinations in Nepal: need for intervention. Kath Univ Med J (KUMJ). 2008;6:399-405.

28. Mishra P, Subish P, Gupta S, Shankar PR, Bista D, Chhetri AK, Bhandari RB. Pattern and economic impact of cutaneous adverse drug reactions; initial experiences from the regional pharmacovigilance center, Western Nepal. Int $\mathrm{J}$ Risk Saf Med. 2006;18:163-171.

29. Ghosh S, Acharya LD, Rao PGM. Study and evaluation of the various cutaneous adverse drug reactions in Kasturba hospital, Manipal. Ind J Pharm Sci. 2006;68:212-215. 